\title{
Role of Stem Cells in Treatment of Acanthamoebic Corneal Ulcer
}

\author{
Khadiga Ahmed Ismail ${ }^{1,2 *}$, Yousry Abdel-hameid Hawash ${ }^{1,3}$, Ahmed Mahmoud Khalifa ${ }^{4}$ and Osama Mahmoud \\ Khalifa $^{4}$
}

${ }^{1}$ Laboratory Medicine Department, Taif University, Saudi Arabia

${ }^{2}$ Department of Parasitology, Ain-Shams University, Egypt

${ }^{3}$ Department Parasitology, Menoufia University, Egypt

${ }^{4}$ Faculty of Medicine, Ain-Shams University, Egypt

Submission: November 06, 2018; Published: December 11, 2018

*Corresponding author: Khadiga Ahmed Ismail, Laboratory Medicine Department, Taif University, Saudi Arabia, Faculty of Applied Medical Sciences, Postal code: 21944, P.O. Box 2425, Egypt

\begin{abstract}
Regeneration of lost human tissue is well known, the research on regenerative medicine has gained scientific advancements. The growing understanding of biological concepts in the regeneration of ocular tissues as well as experiments on stem cells result in shift in the treatment of corneal diseases. Stem cells have been successfully isolated from variety of human tissues including mesenchymal tissues. Initial evidence from several studies has documented the likely breakthrough that stem cells offer for various life-threatening diseases that have so far defeated modern medical care. So, this research aimed to study the role of stem cells in treatment of Acanthamoebic corneal ulcer.

Test experiment included Acanthamoeba-infected female albino rats started local treatment by chlorhexidine $0.02 \%$ after 2 weeks post infection and mesenchymal stem cells (MSCs) injected. Female rats were subdivided into 4 groups. Group (Gp) I: 15 rats infected and injected with MSCs intravenously at 2 weeks post-infection. Gp II: 15 rats infected and intravenously injected with MSCs at 3 weeks post-infection. Gp III: 15 rats infected and injected locally subconjunctival at 2 weeks post-infection. Gp IV: 15 rats infected and locally subconjunctival injected at 3 weeks post-infection with MSCs. Control groups were composed of age- and weight-matched control female rats, subdivided into: Gp V, Gp VI, Gp VII, and Gp VIII. Gp V was composed of 10 Acanthamoeba-infected and non-injected (non- treated negative control) rats. Each 10 of them was sacrificed on dates corresponding to sacrifice dates of each test groups (at one-week post treatment). Gp VI is composed of 10 rats infected and intravenously injected by PBS (vehicle). Each were sacrificed on dates corresponding to sacrifice dates of Gp I and II (at one-week post treatment). Gp VII: 10 rats infected and locally subconjunctival injected by PBS (vehicle). Each 10 was sacrificed on dates corresponding to sacrifice dates of Gp III and IV (at one-week post treatment). Gp VIII: 10 Acanthamoeba-infected and locally treated by chlorhexidine $0.02 \%$ positive control rats which are infected and not injected with MSCs. Each 10 of them was sacrificed on dates like sacrifice dates of each test group (at one-week post treatment). Rates were sacrificed on the planned dates, then corneal specimens and blood samples were collected. There were significant decrease in the level of vascular endothelial growth factor (VEGF) in group I, III and highly significant decrease in the level of nitric oxide (NO) in group I, II, III in comparison to positive control group VIII .There were $20 \%$ engraftments with MSC in group I. Treatment of Acanthamoeba corneal ulcer with chlorhexidine $0.02 \%$ and MSCs accelerated regeneration of the corneal epithelium and restored the antioxidant protective mechanism.
\end{abstract}

Keywords: Stem cells; Acanthamoeba spp; Corneal ulcer

\section{Introduction}

Cornealinjury caused by chemical or thermalburns, mechanical injury, invading microorganism as Acanthamoeba and immune or hereditary disorders results in corneal inflammation, ulceration, neovascularization, conjunctivalization, and stromal scarring, all of which may lead to blindness. Current treatment strategies include anti-inflammatory drug administration, stem cell transplantation, and corneal transplantation. However, these treatments have certain clinical limitations. Anti- inflammatory drugs are not sufficient to suppress angiogenesis, conjunctivalization, and corneal scarring [1]. Corneal transplantation remains the main and effective method for visual rehabilitation once a disease has affected corneal clarity [2]. Even though corneal transplantation is the most successful solid organ transplantation, immune rejection is still the major cause of graft failure. Over the last decade, mesenchymal stem cells (MSCs) treatment has been proposed and used as a possible treatment strategy for cardiovascular diseases, renal wound repair, diabetes, systemic lupus erythematosus, and solid organ transplantation [3]. MSCs are a promising stem cell population because of their self-renewal, pluripotential capability, low immunogenicity properties, and notable immunomodulatory and anti-inflammatory activities. Methods for the isolation and proliferation of MSCs are also simple. MSCs are mainly derived from bone marrow tissue. MSCs can also be isolated form niche of other tissues, including corneal limbal stroma [4]. 
Acanthamoeba is an opportunistic amphizoic protozoan, which is found in the environmental sources. Acanthamoeba can be found in quite different media including sea water, treated water, swimming pool, aquarium, bottled water, soil, air dust, sewage water, contact lenses washing solution, food stuff, air conditioners and dialysis machines [5]. This protozoan can enter the human body in the form of cyst or trophozoite via polluted water, soil or air [6]. Several studies have reported that Acanthamoeba can attack to central nerve system (CNS) leading to granulomatous encephalitis. Acanthamoeba also target other organs such as eye, which end up with amoebic keratitis, as well as skin lesions in the patients with immunodeficiency, and in healthy individuals [7]. Lack of awareness about proper washing, disinfecting contact lenses and use of polluted contact lens solution with Acanthamoeba causes Acanthamoeba keratitis. Therefore, the knowledge of contact lenses wearer about maintenance of contact lenses is very critical. The presence of other microorganisms accompanied with Acanthamoeba in contact lenses has a considerable role in the increase of number of trophozoite adhesion to lenses and thus the increase prevalence of Acanthamoeba keratitis (AK) [8]. Early diagnosis and treatment of AK are essential for improving the visual outcome of patients [9].

The gold standard of diagnosis is cultivation of Acanthamoebae from corneal scrapings. The recommended technique for cultivation is the use of non-nutrient agar covered with a bacterial lawn [10]. However, cultivation is a slow process and needs a long incubation time [11]. Conventional polymerase chain reaction (PCR) has been found to be rapid, sensitive and can be done with a small amount of the specimen [12].

Treatment of AK has been successful using a variety of drugs. Brolene is found to be effective but may be accompanied by drug toxicity and development of resistance [11]. Polyhexamethylene biguanide and chlorhexidine have been proved to be effective with treatment success of $78 \%$ and $86 \%$ respectively [13]. However, side effects in the form of cataract, iris atrophy and peripheral ulcerative keratitis have been attributed to the use of those drugs [14]. Acanthamoeba strains have been identified and isolated from Wadi Hanifah fresh water in Saudi Arabia [15]. This research aimed to study the MSCs role in the treatment of corneal ulcer caused by Acanthamoeba.

\section{Materials and Methods}

\section{Isolation of Acanthamoeba from Corneal Scrapings}

Corneal scrapings were obtained from patients attending ophthalmology out patient's department, who were clinically suspected to have Acanthamoeba keratitis

\section{Culture of the Obtained Samples}

The obtained corneal samples were inoculated onto nonnutrient agar plates covered with a lawn of Escherichia coli [10].

\section{Animal Groups}

A total of 100 healthy albino female rats weighing approximately 200- 250 grams. All animals were fed standard diet and drinking water. All rats were housed five per cage, with a temperature and relative humidity maintained within the target range of $18^{\circ} \mathrm{C}$ to $22^{\circ} \mathrm{C}$ and $40 \%$ to $70 \%$, respectively, and a 12 -h light/dark cycle. Intra- stromal corneal injection of $1 \mu \mathrm{l}$ of Acanthamoeba suspension containing 1 x 106 parasites/ ml. Injection were done under general anesthesia in one eye of each rat.

\section{The Animals are Divided into Groups}

The experiment included 4 groups of Acanthamoeba-infected (confirmed by slit lamp examination and start local treatment by chlorhexidine $0.02 \%$ after 2 weeks post infection) and MSCs injected female rats which were subdivided into 4 groups. Group (Gp) I: 15 rat infected and injected with MSCs intravenously at 2 weeks post- infection. Gp II: 15 rats infected and intravenously injected with MSCs at 3 weeks post-infection. Gp III: 15 rats infected and injected locally subconjunctival at 2 weeks post-infection. Gp IV: 15 rats infected and locally subconjunctival injected at 3 weeks post-infection with MSCs. Control groups were composed of ageand weight- matched control female rats, subdivided into: Gp V, Gp VI, Gp VII, and Gp VIII. Gp V was composed of 10 Acanthamoebainfected and non-injected (non-treated) rats. Each 10 of them was sacrificed on dates corresponding to sacrifice dates of each test groups (at one-week post treatment). Gp VI is composed of 10 rats infected and intravenously injected by PBS (vehicle). Each were sacrificed on dates corresponding to sacrifice dates of Gp I and II (at one-week post treatment). Gp VII: 10 rats infected and locally injected by PBS (vehicle). Each 10 was sacrificed on dates corresponding to sacrifice dates of Gp III and IV (at one-week post treatment). Gp VIII: 10 Acanthamoeba-infected and locally treated by chlorhexidine $0.02 \%$ positive control rats which are infected and not injected with MSCs. Each 10 of them was sacrificed on dates like sacrifice dates of each test group (at one-week post treatment). Rats were sacrificed on the planned dates, then corneal and blood specimens were collected.

\section{Preparation of the Stem Cells}

Bone marrow were obtained under aseptic conditions. Tibiae and femurs of 6-wk-old donor male rat were thoroughly washed by sterile phosphate-buffered saline (PBS). Bone marrow cavities were flushed by Dulbecco's Modified Eagle's Medium (DMEM, Lonza, Switzerland) supplemented with 15\% fetal bovine serum (Lonza, Switzerland) into a sterile petri-dish. Nucleated cells were isolated and resuspended in DMEM culture medium supplemented with $1 \%$ penicillin- streptomycin (Lonza, Switzerland) and sterile sodium bicarbonate $7.5 \%$ aqueous solution (Lonza, Switzerland). Cells were incubated at $37^{\circ} \mathrm{C}$ in $5 \%$ humidified $\mathrm{CO}_{2}$ and were examined daily by inverted microscope. Trypsinization and cell viability testing were done by $9-10$ days when cell count reaches a final concentration of 5-8 $\times 10^{6} / \mathrm{ml}$. A single dose of 500,000 male-derived, non-fractionated MSCs suspended in PBS were injected into each Acanthamoeba-infected female rat by a sterile insulin needle.

\section{Corneas were Scraped and Subjected to the Following}

Conventional PCR assay: Genomic DNA were extracted from the rat corneal tissue homogenate in each group, using Wizard 
Genomic DNA purification kit (Promega, Madison, Wisconsin). The presence or absence of the sex determination region on male $Y$ chromosome (sry) gene in recipient female rat was assessed by PCR. PCR products will be separated using $2 \%$ agarose gel electrophoresis and stained with ethidium bromide. Positive (rat male genomic DNA) and negative (female genomic DNA) controls were included in each assay.

Enzyme-Linked Immunosorbent Assay (ELISA): VEGF protein levels in the corneas were determined using a rat VEGF ELISA Kit (rVEGF-ELISA) Cat. No. EK0540. The corneas were cut into small pieces, and the tissue was homogenized with a mortar. The samples were lysed in $500 \mu$ l of extraction buffer and centrifuged at 10,000 rpm for 10 minutes. The supernatants were used for ELISA. Measurements were conducted according to the instructions of the kit.in summary samples and standards were added and incubated the strips at $37^{\circ} \mathrm{C}$ for 90 minutes. Then add biotinylated antibodies and incubate the strips at $37^{\circ} \mathrm{C}$ for 60 minutes. After that wash strips 3 times with $0.01 \mathrm{M}$ TBS. then add $\mathrm{ABC}$ working solution and incubate the strips at $37^{\circ} \mathrm{C}$ for 30 minutes. Wash strips 5 times with $0.01 \mathrm{M}$ TBS. After that add TMB color developing agent and incubate the strips at $37^{\circ} \mathrm{C}$ in dark for 25-30 minutes. Finally add TMB stop solution and read. VEGF concentrations were expressed as $\mathrm{pg} / \mathrm{ml}$.

\section{Determination of Serum NO Levels}

Serum nitrate concentration as a stable end-product of nitric oxide was measured by an endpoint one-step enzymatic assay using nitrate reductase. The concomitant reduction of nitrate to nitrite by NADPH was monitored by the oxidation of the coenzyme and the decrease in absorbance at $340 \mathrm{~nm}$. The concentrations measured in Mol/L. All blood samples for NO level estimation were withdrawn after overnight fasting $(12 \mathrm{~h})$ to omit nitrates from external sources.

\section{Data Interpretation}

The statistical analysis was done using Statistical Package for Social Science (SPSS for windows; SPSS Inc, Chicago, Illinois). Data were presented as mean \pm standard error (SE). The means were analyzed by one-way ANOVA followed by Bonferonni post hoc test. The difference was considered significant when the P-value is $<0.05$.

\section{Results}

Results shown in Figures 1-3 and Tables 1-9.

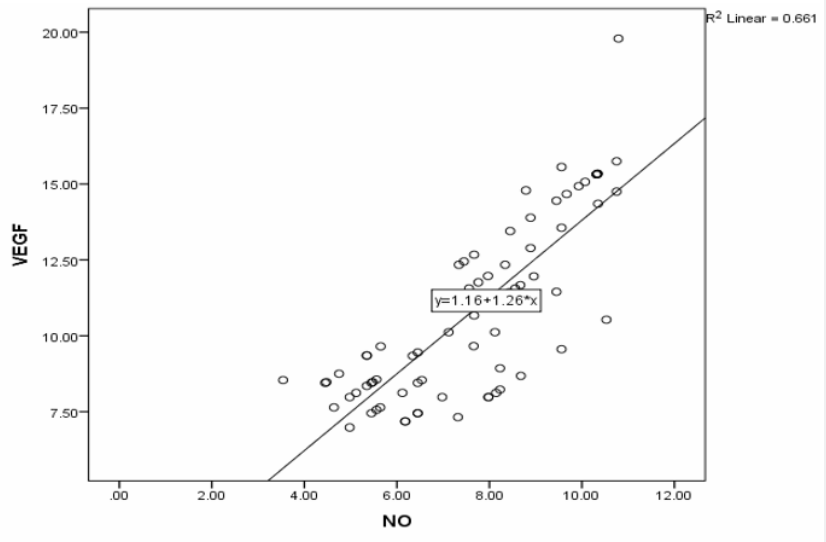

Figure 1: Correlation of VEGF and NO Level in Study Groups.

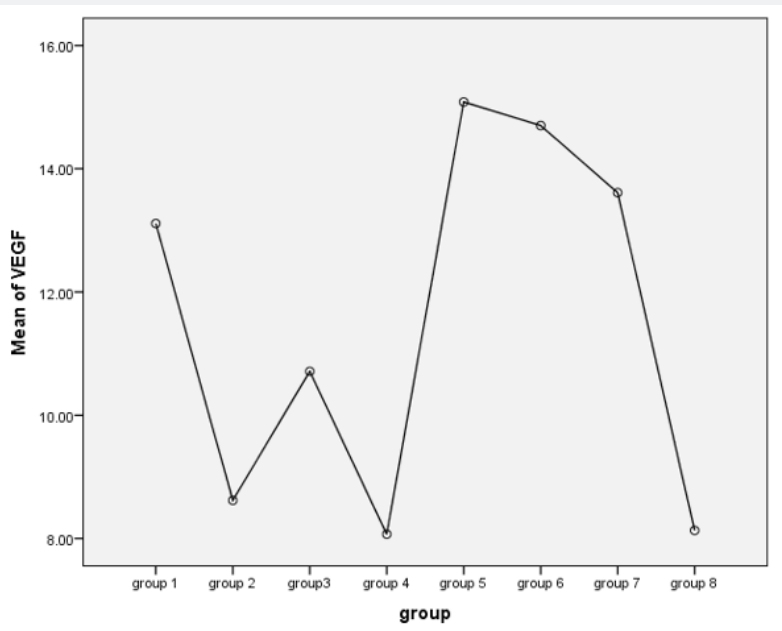

Figure 2: Mean Levels of VEGF in Study Groups. 


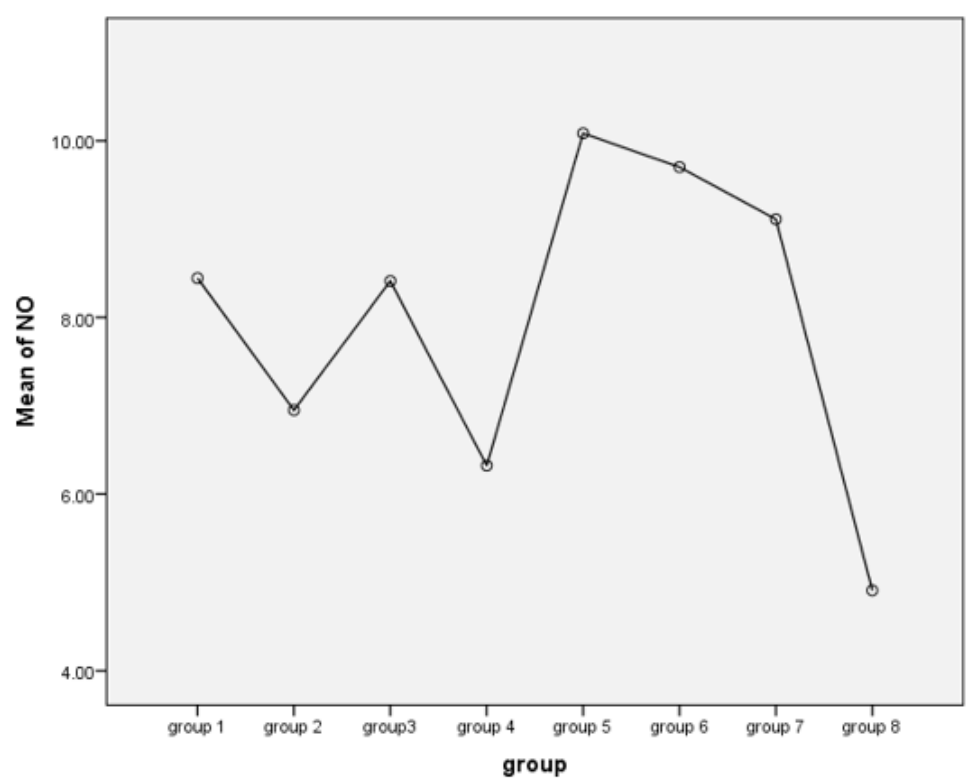

Figure 3: Mean Levels of NO in Study Groups.

Table 1: Compare VEGF level in group I to other groups.

\begin{tabular}{|c|c|c|c|c|}
\hline & Test Statistic \pm S.E. & \multirow{2}{*}{ Sig. } & \multicolumn{2}{|c|}{ 95\% Confidence Interval } \\
\cline { 3 - 5 } & & & Lower Bound & Upper Bound \\
\hline Group 1 Vs Group II & $4.491 \pm 0.599$ & $0.000 \mathrm{a}$ & 2.6147 & 6.368 \\
\hline Group 1 Vs Group III & $2.398 \pm 0.641$ & $0.009 \mathrm{~b}$ & 0.3914 & 6.406 \\
\hline Group 1 Vs Group IV & $5.040 \pm 0.611$ & $0.000 \mathrm{c}$ & 3.1263 & 0.522 \\
\hline Group 1 Vs Group V & $1.973 \pm 0.796$ & $0.224 \mathrm{~d}$ & 4.468 & 3.935 \\
\hline Group 1 Vs Group VI & $1.590 \pm 0.748$ & $0.410 \mathrm{e}$ & 2.845 & 1.843 \\
\hline Group 1 Vs Group VII & $0.500 \pm 0.748$ & $0.998 \mathrm{f}$ & 2.9117 & 7.046 \\
\hline Group 1 Vs Group VIII & $4.979 \pm 0.660$ & $0.000 \mathrm{~g}$ & & \\
\hline
\end{tabular}

a: Highly significant decrease in VEGF level in group I in comparison to group II $(p<0.001)$

b: Significant decrease in VEGF level in group I in comparison to group III $(p<0.05)$

c: Highly significant decrease in VEGF level in group I in comparison to group IV $(p<0.001)$

$d$ : Non-significant decrease in VEGF level in group I in comparison to group $V(p>0.05)$

e: Non-significant decrease in VEGF level in group I in comparison to group VI $(p>0.05)$

Table 2: Compare VEGF level in group II to other groups

\begin{tabular}{|c|c|c|c|c|}
\hline & \multirow{2}{*}{ Test Statistic \pm S.E. } & \multirow{2}{*}{ Sig. } & \multicolumn{2}{|c|}{ 95\% Confidence Interval } \\
\cline { 3 - 5 } & & & Lower Bound & Upper Bound \\
\hline Group II Vs Group III & $2.092 \pm 0.629$ & $0.030 \mathrm{a}$ & 4.064 & 2.12 \\
\hline Group II Vs Group IV & $0.548 \pm 0.599$ & $0.983 \mathrm{~b}$ & 1.328 & 3.997 \\
\hline Group II Vs Group V & $6.464 \pm 0.787$ & $0.000 \mathrm{c}$ & 8.932 & 3.768 \\
\hline Group II Vs Group VI & $6.082 \pm 0.738$ & $0.000 \mathrm{~d}$ & 8.396 & 2.678 \\
\hline Group II Vs Group VII & $4.992 \pm 0.738$ & $0.000 \mathrm{e}$ & 7.306 & 2.52 \\
\hline Group II Vs Group VIII & $0.487 \pm 0.649$ & $0.995 \mathrm{f}$ & 1.545 & 2 \\
\hline
\end{tabular}

a: Significant decrease in VEGF level in group II in comparison to group III $(p<0.05)$

b: Non significant decrease in VEGF level in group II in comparison to group IV ( $p>0.05)$

c: Highly significant decrease in VEGF level in group II in comparison to group V $(p<0.001)$

d: Highly significant decrease in VEGF level in group II in comparison to group VI $(p<0.001)$

e: Highly significant decrease in VEGF level in group II in comparison to group VII $(p<0.001)$

$\mathrm{f}$ : Non significant decrease in VEGF level in group I in comparison to group VIII ( $p>0.05)$ 
Table 3: Compare VEGF level in group III to other groups.

\begin{tabular}{|c|c|c|c|c|}
\hline & Test statistic \pm S.E. & \multirow{2}{*}{ Sig. } & \multicolumn{2}{|c|}{ 95\% Confidence Interval } \\
\cline { 3 - 5 } & & & Lower Bound & Upper Bound \\
\hline Group III Vs Group IV & $2.641 \pm 0.641$ & $0.003 \mathrm{a}$ & 0.634 & 4.649 \\
\hline Group III Vs Group V & $4.372 \pm 0.819$ & $0.000 \mathrm{~b}$ & 6.939 & 1.804 \\
\hline Group III Vs Group VI & $3.989 \pm 0.773$ & $0.000 \mathrm{c}$ & 6.41 & 1.568 \\
\hline Group III Vs Group VII & $2.899 \pm 0.773$ & $0.009 \mathrm{~d}$ & 5.32 & 0.478 \\
\hline Group III Vs Group VIII & $2.580 \pm 0.687$ & $0.009 \mathrm{e}$ & 0.426 & 4.734 \\
\hline
\end{tabular}

a: Significant decrease in VEGF level in group III in comparison to group IV $(p<0.05)$

b: Highly significant decrease in VEGF level in group III in comparison to group V $(p<0.001)$

c: Highly significant decrease in VEGF level in group III in comparison to group VI $(p<0.001)$

d: Significant decrease in VEGF level in group III in comparison to group VII $(p<0.05)$

e: Significant decrease in VEGF level in group III in comparison to group VIII $(p<0.05)$

Table 4: Compare VEGF level in group IV to other groups.

\begin{tabular}{|c|c|c|c|c|}
\hline & \multirow{2}{*}{ Test statistic \pm S.E. } & \multirow{2}{*}{ Sig. } & \multicolumn{2}{|c|}{ 95\% Confidence Interval } \\
\cline { 3 - 5 } & & & Lower Bound & Upper Bound \\
\hline Group IV Vs Group V & $7.013 \pm 0.796$ & $0.000 \mathrm{a}$ & 9.509 & 4.517 \\
\hline Group IV Vs Group VI & $6.631 \pm 0.748$ & $0.000 \mathrm{~b}$ & 8.975 & 4.287 \\
\hline Group IV Vs Group VII & $5.541 \pm 0.748$ & $0.000 \mathrm{c}$ & 7.885 & 3.197 \\
\hline Group IV Vs Group VIII & $0.061 \pm 0.660$ & $1.000 \mathrm{~d}$ & 2.128 & 2.006 \\
\hline
\end{tabular}

a: Highly significant decrease in VEGF level in group IV in comparison to group $V(p<0.001)$

b: Highly significant decrease in VEGF level in group IV in comparison to group $\mathrm{VI}(p<0.001)$

c: Highly significant decrease in VEGF level in group IV in comparison to group VII $(p<0.001)$

$\mathrm{d}$ : Non significant decrease in VEGF level in group IV in comparison to group VIII $(p>0.05)$

Table 5: Compare NO level in group I to other groups.

\begin{tabular}{|c|c|c|c|c|}
\hline & \multirow[t]{2}{*}{ Test statistic \pm S.E. } & \multirow[t]{2}{*}{ Sig. } & \multicolumn{2}{|c|}{ 95\% Confidence Interval } \\
\hline & & & Lower Bound & Upper Bound \\
\hline Group 1 Vs Group II & $1.494 \pm 0.483$ & $0.050 \mathrm{a}$ & 0.021 & 3.009 \\
\hline Group 1 Vs Group III & $0.032 \pm 0.517$ & $1.000 \mathrm{~b}$ & 1.588 & 1.653 \\
\hline Group 1 Vs Group VI & $2.121 \pm 0.493$ & $0.001 \mathrm{c}$ & 0.576 & 3.667 \\
\hline Group 1 Vs Group V & $1.639 \pm 0.643$ & $0.194 \mathrm{~d}$ & 3.655 & 0.375 \\
\hline Group 1 Vs Group VI & $1.257 \pm 0.604$ & $0.438 \mathrm{e}$ & 3.15 & 0.635 \\
\hline Group 1 VsGroup VII & $0.667 \pm 0.604$ & $0.954 \mathrm{f}$ & 2.56 & 1.225 \\
\hline Group 1 Vs Group VIII & $3.534 \pm 0.533$ & $0.000 \mathrm{~g}$ & 1.8651 & 5.2041 \\
\hline
\end{tabular}

a: Significant decrease in NO level in group I in comparison to group II $(p<0.05)$

b: Non significant decrease in NO level in group I in comparison to group III $(p>0.05)$

c: Highly significant decrease in No level in group I in comparison to group IV $(p<0.001)$

$d$ : Non significant decrease in NO level in group I in comparison to group $V(p>0.05)$

e: Non significant decrease in NO level in group I in comparison to group $\mathrm{VI}(p>0.05)$

$f:$ Non significant decrease in NO level in group I in comparison to group VII $(p>0.05)$

g: Highly significant decrease in NO level in group I in comparison to group VIII ( $p>0.001)$

Table 6: Compare NO level in group II to other groups.

\begin{tabular}{|c|c|c|c|c|}
\hline & Test Statistic \pm S.E. & \multirow{2}{*}{ Sig. } & \multicolumn{2}{|c|}{ 95\% Confidence Interval } \\
\cline { 3 - 5 } & & & Lower Bound & Upper Bound \\
\hline Group II Vs Group III & $1.462 \pm 0.508$ & $0.095 \mathrm{a}$ & 3.0545 & 0.1305 \\
\hline Group II Vs Group IV & $0.627 \pm 0.483$ & $0.897 \mathrm{~b}$ & 0.8882 & 2.143 \\
\hline Group II Vs Group V & $3.134 \pm 0.636$ & $0.000 \mathrm{c}$ & 5.1263 & 0.141 \\
\hline Group II Vs Group VI & $2.751 \pm 0.596$ & $0.000 \mathrm{~d}$ & 4.6202 & 0.293 \\
\hline Group II Vs Group VII & $2.161 \pm 0.596$ & $0.013 \mathrm{e}$ & 4.03 & 3.682 \\
\hline Group II Vs Group VIII & $2.040 \pm 0.524$ & $0.005 \mathrm{f}$ & 0.398 & \\
\hline
\end{tabular}


a: Non significant decrease in NO level in group II in comparison to group III ( $p>0.05)$

b: Non significant decrease in NO level in group II in comparison to group IV ( $p>0.05)$

c: Highly significant decrease in $\mathrm{NO}$ level in group II in comparison to group V $(p<0.001)$

d: Highly significant decrease in NO level in group II in comparison to group $\mathrm{VI}(\mathrm{p}<0.001)$

e: Significant decrease in NO level in group II in comparison to group VII $(p<0.05)$

f: Significant decrease in NO level in group II in comparison to group VIII $(p<0.05)$

Table 7: Compare NO level in group III to other groups.

\begin{tabular}{|c|c|c|c|c|}
\hline & \multirow[t]{2}{*}{ Test Statistic \pm S.E. } & \multirow[t]{2}{*}{ Sig. } & \multicolumn{2}{|c|}{ 95\% Confidence Interval } \\
\hline & & & Lower Bound & Upper Bound \\
\hline Group III Vs Group IV & $2.089 \pm 0.517$ & $0.003 a$ & 0.4684 & 3.71 \\
\hline Group III Vs Group V & $1.672 \pm 0.662$ & $0.204 \mathrm{~b}$ & 3.745 & 0.401 \\
\hline Group III Vs Group VI & $1.289 \pm 0.624$ & $0.447 \mathrm{c}$ & 3.244 & 0.665 \\
\hline Group III Vs Group VII & $.6996 \pm 0.624$ & $0.950 \mathrm{~d}$ & 2.654 & 1.255 \\
\hline Group III Vs Group VIII & $3.502 \pm 0.555$ & $0.000 \mathrm{e}$ & 1.762 & 5.242 \\
\hline
\end{tabular}

a: Significant decrease in NO level in group III in comparison to group IV $(p<0.001)$

b: Non significant decrease in NO level in group III in comparison to group V $(p>0.05)$

c: Non significant decrease in NO level in group III in comparison to group VI $(p>0.05)$

d: Non significant decrease in NO level in group III in comparison to group VII ( $p>0.05)$

e: Highly significant decrease in NO level in group III in comparison to group VIII $(p<0.001)$

Table 8: Compare NO level in group IV to other groups.

\begin{tabular}{|c|c|c|c|c|}
\hline & \multirow{2}{*}{ Test Statistic \pm S.E. } & \multirow[t]{2}{*}{ Sig. } & \multicolumn{2}{|c|}{ 95\% Confidence Interval } \\
\hline & & & Lower Bound & Upper Bound \\
\hline Group IV Vs Group V & $3.7614 \pm 00.643$ & $0.000 \mathrm{a}$ & 5.776 & 1.746 \\
\hline Group IV Vs Group V & $3.379 \pm 0.604$ & $0.000 \mathrm{~b}$ & 5.272 & 1.486 \\
\hline Group IV Vs Group VII & $2.789 \pm 0.504$ & $0.000 \mathrm{c}$ & 4.682 & 0.896 \\
\hline Group IV Vs Group VIII & $1.413 \pm 0.533$ & $0.157 \mathrm{~d}$ & 0.256 & 3.0825 \\
\hline
\end{tabular}

a: Highly significant decrease in NO level in group IV in comparison to group $\mathrm{V}(\mathrm{p}<0.001)$

b: Highly significant decrease in NO level in group IV in comparison to group $\mathrm{VI}(\mathrm{p}<0.001)$

c: Highly significant decrease in NO level in group IV in comparison to group VII $(p<0.001)$

d: Non-significant decrease in NO level in group IV in comparison to group VIII $(p>0.05)$

Table 9: Number and percentage of engraftment among study groups.

\begin{tabular}{|c|c|c|}
\hline & Number of Engraftments & Percentage \\
\hline Group I & 3 & $20 \%$ \\
\hline Group II & 2 & $13 \%$ \\
\hline Group III & 3 & $20 \%$ \\
\hline Group IV & 1 & $6.50 \%$ \\
\hline
\end{tabular}

\section{Discussion}

Acanthamoeba was first recognized as an ocular pathogen in 1973 and was the cause of an epidemic in the 1980s due to contaminated contactlenses [16]. A variety of drugs have been used for treatment of AK including chlorhexidine, polyhexamethylene biguanide, propamidine isethionate, dibromopropamidine isethionate, neomycin, paromomycin, polymyxin $\mathrm{B}$, clotrimazole, ketoconazole, miconazole and itraconazole [17]. Miltefosine, a hexadecylphosphocholine, has also been shown to have amoebicidal potential [18]. Treatment failures occur and may be due to inherent or acquired resistance perhaps attributed to strain and species susceptibility differences or to advanced corneal disease [16]. MSCs are a promising stem cell population because of their self-renewal, pluripotential capability, low immunogenicity properties, and notable immunomodulatory and anti-inflammatory activities [11].

In this research, treatment of Acanthamoeba corneal ulcer by chlorhexidine $0.02 \%$ and MSCs which were injected through different ways intravenous and subconjunctival and in different time post infection. The stem cells migrate into the damaged corneal surface by Acanthamoeba infection and support corneal healing as there were decrease in the level of inflammatory mediators as VEGF and NO. Our results showed that the treatment of Acanthamoba corneal ulcers with combined chlorhexidine $0.02 \%$ and MSCs restored the regenerated corneal epithelium as showed in Table $1 \& 3$. This was accompanied by highly reduced neovascularization this in agreement of the study of Ma et al. [19] they concluded that the treatment effect of MSCs was a result of the inhibition of inflammation and angiogenesis rather than epithelial differentiation.

The protection of the cornea against toxic environmental influences after the injury of the cornea is due to the antioxidant mechanism located in the corneal epithelium which is very important [20]. Besides the immunomodulatory and antiinflammatory properties of MSCs, these stem cells reveal 
important antioxidant effects. MSCs can exert direct antioxidant activities through the secretion of antioxidant molecules. In this study there were significant decrease in NO level in MSCs treatment the expressions of antioxidant enzymes were restored and balanced with prooxidant enzymes in the epithelium, this may be one mechanism supporting corneal reepithelialization and healing. In Acanthamoeba infected corneas treated with stem cells the levels of NO were significantly decreased compared to control group as in Tables 5-7 this in agreement with study done by Bassi et al. [21].

There was good response at early stage of intervention as the percentage of engraftments increased as showed in Table 9 which in agreements of study done by Crop et al. [22], they showed that infusion time is an important factor for MSCs to effectively exert their treatment function. Cejka et al. [20], demonstrated that there was positive correlation between level of VEGF and NO which goes with our results as in Figure 1.

\section{Conclusion}

MSCs transferred onto the damaged corneal surface early after Acanthamoeba infection, accelerated corneal re-epithelialization and restored the regenerated corneal epithelium and providing potential new modality for the treatment of corneal ulcer caused by Acanthmoeba [23]. Corneal inflammation was suppressed, and corneal neovascularization reduced as there were significant decrease in the VEGF and NO. the efficacy of stem cell treatment of Acanthamoeba infection corneal ulcer were marked in early stage of infection than late stage of infection. So, it is recommended to start treatment early and the dose of MSCs is another element that influences the response to treatment further study could use other doses and evaluate response to achieve the best results.

\section{Acknowledgment}

This study was supported by a research grant (Project No. 1-438-5598) through the Research Support of Taif University, Saudi Arabia. The funders had no role in study design, data collection and analysis, decision to publish, or preparation of the manuscript.

\section{Conflict of Interest}

There is no Conflict of interest.

\section{Ethical Approval}

All animal studies were approved by Taif University Ethics Committee for Animal Experiments. The research was conducted in full compliance with the Helsinki Statement for the Use of Animals in research.

\section{References}

1. Reinhard T, Spelsberg H, Henke L et al. (2004) Long-term results of allogeneic penetrating limbo-keratoplasty in total limbal stem cell deficiency. Ophthalmology 111(4): 775-778.

2. Tan DT, Dart JK, Holland EJ, Kinoshita S (2012) Corneal transplantation. Lancet 379(9827): 1749-1761.

3. Cashman TJ, Gouon-Evans V, Costa KD (2013) Mesenchymal stem cells for cardiac therapy: practical challenges and potential mechanisms. Stem Cell Rev 9(3): 254-265.

4. Stewart MC, Stewart AA (2011) Mesenchymal stem cells: characteristics, sources, and mechanisms of action. Vet Clin North Am Equine Pract 27(2): 243-261.

5. Marciano F, Cabral G (2003) Acanthamoeba spp. as agents of disease in humans. Clin Microbiol Rev 16(2): 273-230.

6. Edrisian GH, Rezaian M, Ghorbani M (2008) Medical protozology. (1 $1^{\text {st }}$ edn). Published Tehran University of medical sciences :120-121.

7. Steinberg J, Galindo R, Kraus E (2002) Disseminated acanthamoebiasis in a renal transplant recipient with osteomyelitis and cutaneous lesions: case report and literature review. Clin Infect Dis 35(5): 43-49.

8. Winiecka-Krusnell J, Linder E (2001) Bacterial infections of free-living amoebae. Res Microbiol 152(7):613-619.

9. Cardine S, Bourcier T, Chaumeil C et al. (2002) Clinical management and prognosis in Acanthamoeba keratitis. a retrospective study of 25 cases. J Fr Ophtalmol 25(10): 1007-1013.

10. Schuster FL (2002) Cultivation of pathogenic and opportunistic freeliving amoebas. Clin Microbiol Rev 15(3): 342-335.

11. Schuster FL, Visvesvara GS (2004a) Free-living amoebae as opportunistic and non-opportunistic pathogens of humans and animals. Int J Parasitol 34(9): 1001-1027.

12. Safar EH (2010) Involvement of the eye with Acanthamoeba. JASMR 5(2): 191-198.

13. Lim N, Goh D, Bunce C, xing w, Fraenkel G, et al. (2008) Comparison of Polyhexamethylene Biguanide and Chlorhexidine as Monotherapy Agents in the Treatment of Acanthamoeba Keratitis. Am J Ophthalmol 145(1): 130-135

14. Dart JK, Saw V, Kilvington S (2009) Acanthamoeba keratitis: Diagnosis and treatment update. Am J Ophthalmol 148(4): 487-499.

15. Al-Herrawy AZ, and Al Rasheid KA (1998) Identification of Acanthamoeba strains isolated from a freshwater course in Saudi Arabia. J Egypt Public Health Assoc 73(5-6): 621-633.

16. O'Day DM, Head WS (2000) Advances in the management of keratomycosis and Acanthamoeba keratitis. Cornea 19(5): 681-687.

17. Schuster FL, Visvesvara GS (2004b) Opportunistic amoebae: challenges in prophylaxis and treatment. Drug Resistance Updates 7(1): 41-51.

18. Walochnik J, Duchene M, Seifert K, Obwaller A, Hottkowitz T, et al. (2002) Cytotoxic activities of alkylphosphocholines against clinical isolates of Acanthamoeba spp. Antimicrob Agents Chemother 46(3): 695-701.

19. Ma Y, Xu Y, Xiao Z, Yang W, Zhang C, et al. (2006) Reconstruction of chemically burned rat corneal surface by bone marrow- derived human mesenchymal stem cells. Stem Cells 24(2): 315-321.

20. Cejka C, Holan V, Trosan P, Zajicova A, Javorkova E, et al. (2016) The favorable effect of mesenchymal stem cell treatment on the antioxidant protective mechanism in the corneal epithelium and renewal of corneal optical properties changed after alkali burns. Oxid Med Cell Longev 2016: 5843809.

21. Bassi ÊJ, de Almeida DC, Moraes-Vieira PM, Câmara NO (2012) Exploring the role of soluble factors associated with immune regulatory properties of mesenchymal stem cells. Stem Cell Rev 8(2): 329-342.

22. Crop M, Baan C, Weimar W, Hoogduijn M (2009) Potential of mesenchymal stem cells as immune therapy in solid-organ transplantation. Transpl Int 22(4): 365-376.

23. Vural A, Polat ZA, Topalkara A, Toker MI, Erdogan H, et al. (2007) The effect of propolis in experimental Acanthamoeba keratitis. Clin Exp Ophthalmol 35(8): 749-754. 
This work is licensed under Creative Commons Attribution 4.0 License

DOI: 10.19080/CTBEB.2018.17.555963

\section{Your next submission with Juniper Publishers} will reach you the below assets

- Quality Editorial service

- Swift Peer Review

- Reprints availability

- E-prints Service

- Manuscript Podcast for convenient understanding

- Global attainment for your research

- Manuscript accessibility in different formats ( Pdf, E-pub, Full Text, Audio)

- Unceasing customer service

Track the below URL for one-step submission https://juniperpublishers.com/online-submission.php 